\title{
Basal cell carcinoma of the skin with areas of squamous cell carcinoma: a basosquamous cell carcinoma?
}

\author{
J LOPES DE FARIA
}

Department of Anatomical Pathology, Faculdade de Ciências Médicas, UNICAMP, Campinas, SP, Brazil

SUMmARY The diagnosis of basosquamous cell carcinoma is controversial. A review of cases of basal cell carcinoma showed 23 cases that had conspicuous areas of squamous cell carcinoma. This was distinguished from squamous differentiation and keratotic basal cell carcinoma by a comparative study of 40 cases of compact lobular and 40 cases of keratotic basal cell carcinoma. Areas of intermediate tumour differentiation between basal cell and squamous cell carcinoma were found. Basal cell carcinomas with areas of squamous cell carcinoma may be called basosquamous carcinoma.

Basal cell carcinomas have been described with nuclear atypia, ${ }^{1}$ multinucleate tumour giant cells, ${ }^{12}$ and other unusual or aggressive features. ${ }^{3}$ Only one case of basal cell carcinoma with areas of squamous cell carcinoma has been reported, and this was termed basosquamous cell carcinoma. ${ }^{4}$ This controversial diagnosis is accepted by some authors $s^{4-8}$ and rejected by others. ${ }^{y-12}$ This paper reports a histopathological study of 23 cases of basal cell carcinoma of skin in which there were conspicuous areas of squamous cell carcinoma.

\section{Material and methods}

Over five years (1974-8) we diagnosed histologically 409 cases of basal cell carcinoma (BCC) of the skin. Thirteen cases had areas of squamous cell carcinoma; 10 new cases with this feature were diagnosed subsequently, making a total of 23 cases. All the patients were white, in the fifth to eighth decades of life, and comprised 14 men and nine women. All the tumours occurred in areas exposed to the sun; 18 were on the face. In most cases the skin was ulcerated at the time of clinical examination. Seven patients had an additional skin carcinoma elsewhere, five of which were BCC and two squamous cell carcinomas (SCC). We compared 40 cases of solid BCC and 40 of keratotic BCC, as defined by Lever and Schaumburg-Lever," as controls. These control cases were studied sequentially, provided there was sufficient material for a suitable histological analysis.

Accepted for publication 1 July 1985
Nine surgical specimens of BCC with areas of SCC were about $5 \mathrm{~mm}$ long, and 14 specimens comprised the entire tumoral mass, and these were all examined histologically. The material was embedded in paraffin, and sections were stained with haematoxylin and eosin, and occasionally with stains for reticulin. In most patients one section from one or more blocks was examined. In a few cases serial sections were also used.

The aggressiveness of basal cell carcinomas and BCCs with areas of SCC was defined by the presence of small cell clusters with spikey outlines and infiltration of cells in cords one and two cells thick. ${ }^{3}$ Statistical evaluation of the results was done using the $\chi^{2}$ test.

\section{Results}

CONTROL GROUPS

Basal cell carcinoma of solid type

The tumours showed the characteristic pattern of compact lobular $\mathrm{BCCs}^{y}$ and consisted of masses of dark staining small cells, with palisading of these cells at the periphery. The cells had little cytoplasm and uniform nuclei. In 29 of 40 patients (73\%) there were a few small cell masses with irregular outlines associated with infiltration of cells in cords one or two cells thick. A few cell masses in 12 of 40 cases (30\%) exhibited occasional atypical cells with very large vesicular nuclei, scanty cytoplasm, and prominent nucleoli (Fig. 1). Mitoses were rare.

Keratotic basal cell carcinoma

The pattern was similar to that of compact lobular 


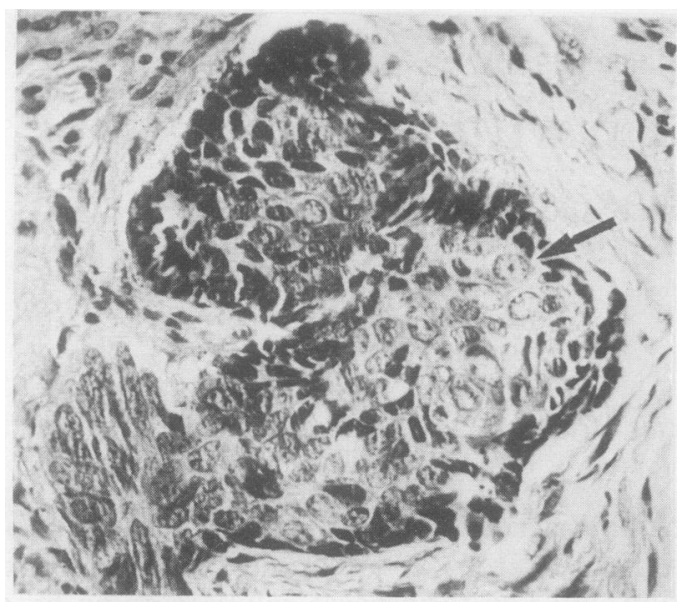

Fig. 1 Control patient with solid basal cell carcinoma. Cluster of basal cell carcinoma has cells with large vesicular nuclei (arrow) and spikey outline. (Hematoxylin and eosin.) $\times 300$.

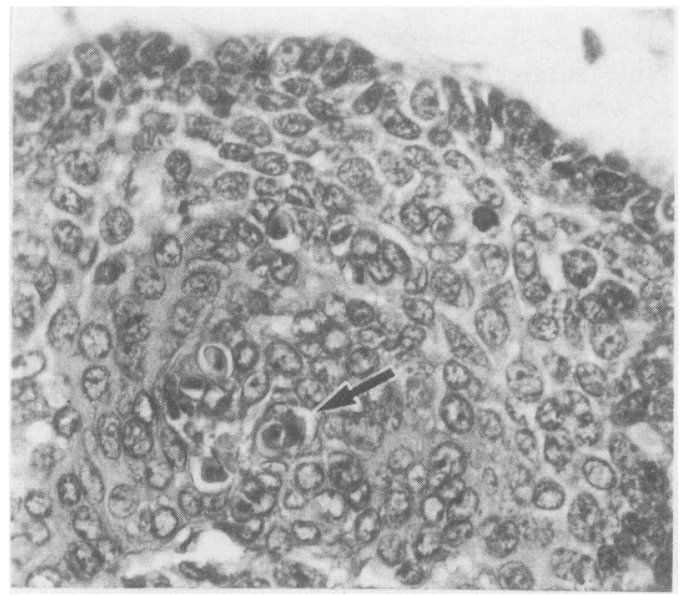

Fig. 2 Control patient with basal cell carcinoma with differentiation of squamoid cells and rare parakeratotic cells (arrow). Notice palisading and uniform appearance of cells. (Hematoxylin and eosin.) $\times 384$.

BCCs, with frequent peripheral palisading. In the centre of the tumour islands there was, however, differentiation of basal cells into intermediate cells with amphophilic cytoplasm and into parakerototic and keratotic squamous cells (Fig. 2). The keratotic cells were single or grouped into "pearls". The nuclei, in general, varied little in size and staining. Cell masses with infiltrative borders, with the infiltration of cells in cords one to two cells thick, were less common than in the compact lobular type of BCC; they were seen in 24 of 40 patients $(60 \%)$. Atypical cells were detected in half the patients (Fig. 3). Mitoses were rare.

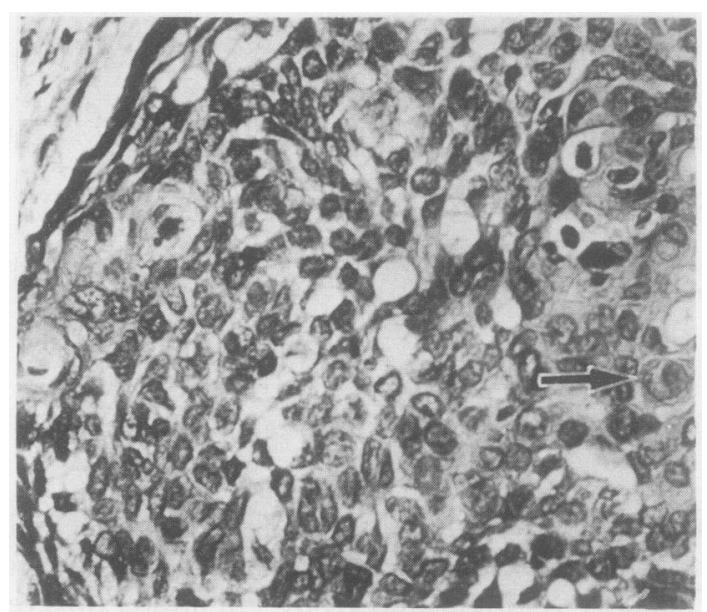

Fig. 3 Control patient with basal cell carcinoma. Cluster of basal cell carcinoma shows darkly stained palisading to the left and differentiation of squamoid cells; on the right atypical cell with large nucleus and scanty cytoplasm (arrow). (Hematoxylin and eosin.) $\times 384$.

Two cases with atypical cells exhibited a special feature: in addition to features of compact lobular BCC with areas of keratotic BCC, there was also one large solid cell mass in each. This consisted of larger and paler staining monotonous intermediate cells with amphophilic cytoplasm, which had little variation in nuclear size but had more numerous atypical cells than those in BCCs of compact lobular type. Palisaded basal cells were found only in part of the periphery of these cell masses.

\section{BASAL CELL CARCINOMAS WITH AREAS OF SQUAMOUS CELL CARCINOMA}

The prevalence of basal cell carcinomas of the skin with areas of squamous cell carcinoma in this series was $3 \%$ (13 of 409 patients). All but four tumours were ulcerated. The tumours had infiltrated the reticular dermis, and some extended as far as striated muscle. The inflammatory reaction in the tissue around the tumour cells consisted mainly of lymphocytes and plasma cells and was rarely severe. Connective tissue proliferation was usually moderate.

In the same section of each specimen there were distinct areas of BCC, SCC, and an intermediate stage of differentiation (Figs. 4 to 10). Most of the tumour comprised BCC with smaller areas of intermediate tissue and occasional areas of SCC. The basal cell carcinoma was solid in eight cases, keratotic in nine, and mixed in six (solid and keratotic in three; solid and adenoid in two; and solid, adenoid, and keratotic in one). Adenoid areas of BCC in the mixed type presented the characteristic features of 


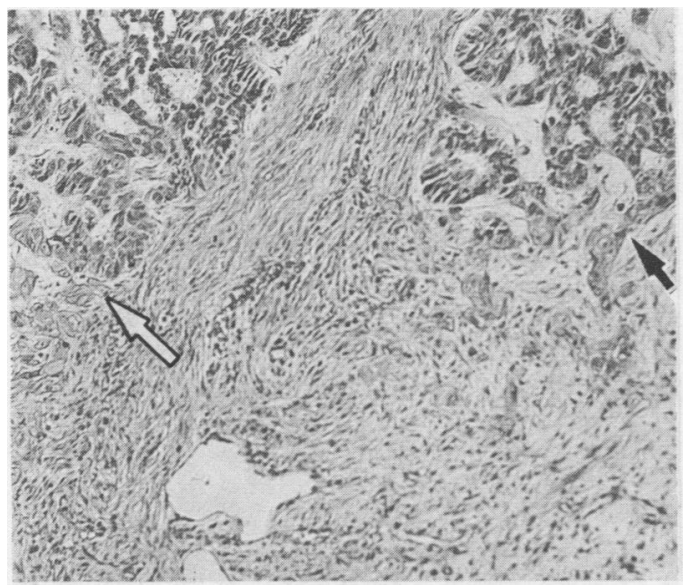

Fig. 4 Adenoid area in mixed basal cell carcinoma showing change into squamous cell carcinoma in the lower dermis (arrows). $\times 96$.

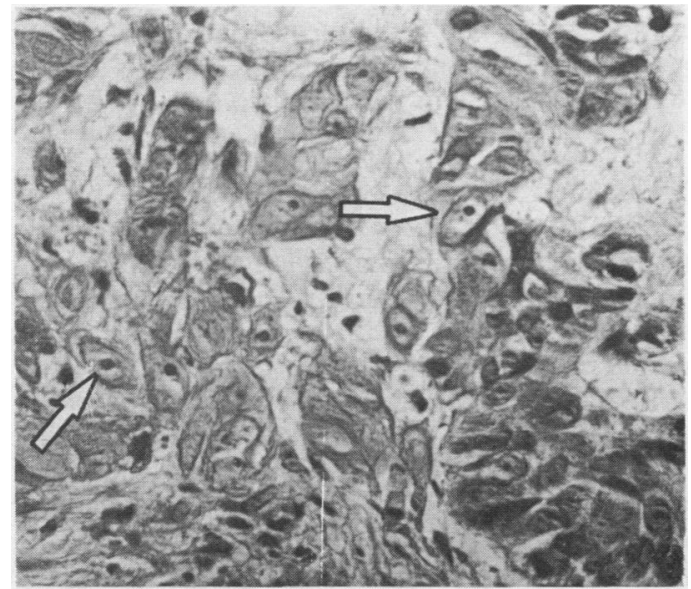

Fig. 5 Higher magnification of Fig. 4 from area indicated by left arrow, showing adenoid tissue to the right and squamous cell carcinoma to the left. Squamous cells present very large, and light nuclei with prominent nucleoli (arrows), and acidophilic cytoplasm. $\times 384$.

adenoid basal cell carcinoma, ${ }^{9}$ and were continuous with the areas of SCC (Figs. 4 and 5).

The areas of squamous cell carcinoma were small and isolated in two thirds of patients, but in the remainder there were two, three, and occasionally five areas of SCC. The size of the squamous areas was generally smaller than that of the areas of BCC or of the intermediate carcinomatous tissue. The size of each area did not usually exceed one field at a magnification of $100 \times$ and was sometimes as small as one field at a magnification of $400 \times$. The areas of SCC were not related to ulceration and were seen deep in the reticular dermis and in striated muscle.

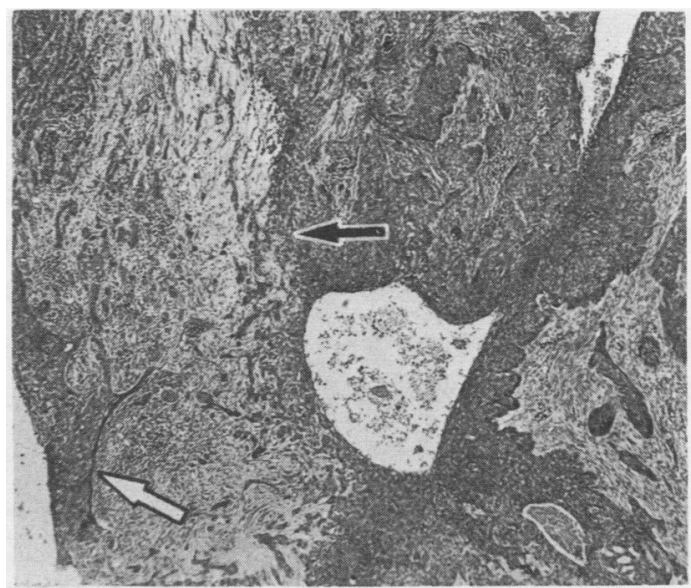

Fig. 6 Basal cell carcinoma with poorly delineated area of squamous cell carcinoma seen between the arrows.

(Hematoxylin and eosin.) $\times 20$.

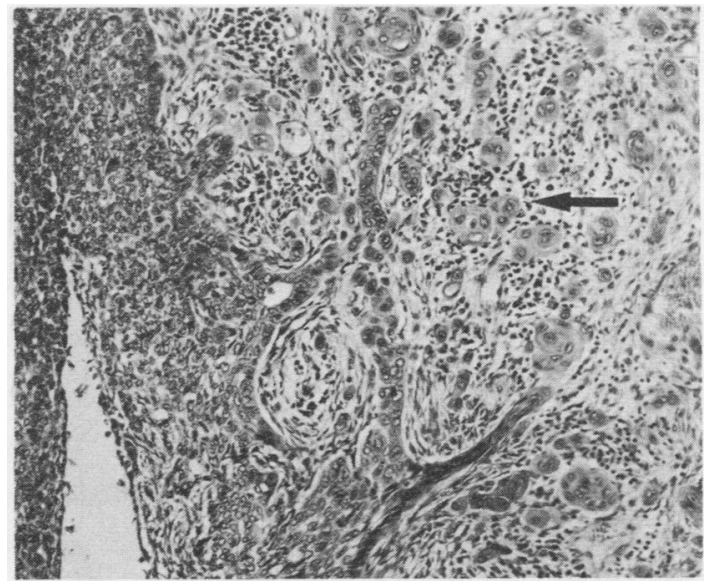

Fig. 7 Higher magnification of Fig. 6, of area indicated by left arrow, showing basal cell carcinoma on the left and squamous cell carcinoma on the right. $\times 80$.

Even the smallest tumour islands had the typical pattern of SCC of the skin, (Figs. 5, 6 and 8). These areas consisted of squamous cells with large nuclei and little cytoplasm. The nuclei showed variation in size and staining. The classification of the SCC in these areas was: grade 2 , nine patients, grade 3,11 , grade 4 , three."

The tumour areas which were of intermediate differentiation were abundant and differed in part from those of typical BCC of the solid or keratotic type or SCC. Aggressive features were common and similar to those described in BCCs. Peripheral palisading of basal cells was, however, generally absent (Fig. 9). The tumour cells with intermediate differentiation were larger and lighter compared with those of 


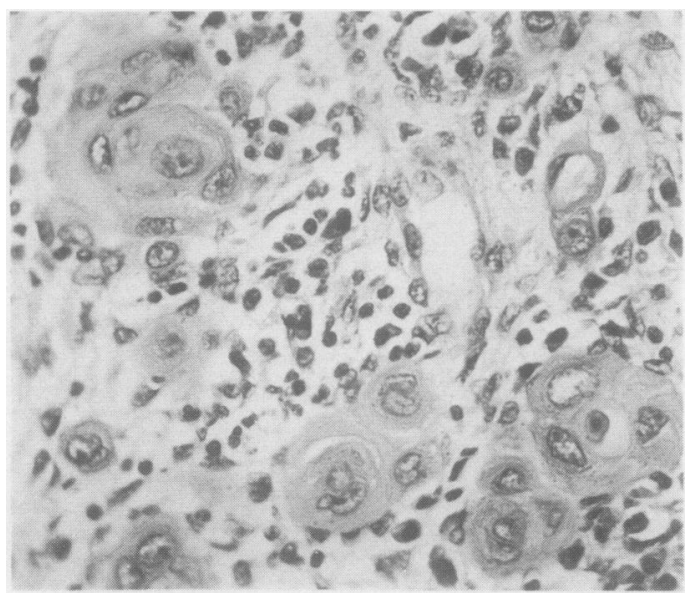

Fig. 8 Higher magnification of Fig. 7, of area indicated by arrow, showing squamous cell carcinoma with infiltration of single cells. $\times 320$.

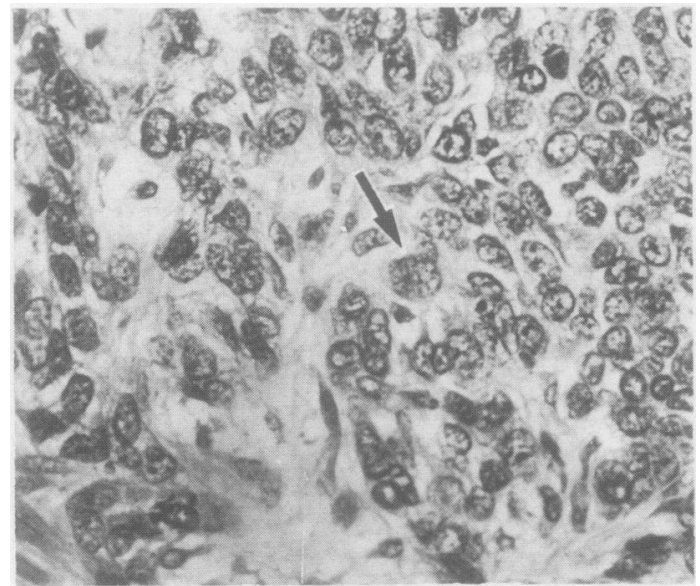

Fig. 9 Higher magnification of Fig. 6 of area indicated by right arrow. Note monotone appearance of intermediate stage carcinomatous tissue without palisading on the left and cells with large nuclei (arrow). $\times 320$

compact lobular BCC; this was due to differentiation into cells with amphophilic cytoplasm or, more rarely, into cells with eosinophilic cytoplasm. Large and atypical cells, as seen in control basal cell carcinomas, were present in the intermediate tumour tissue of all patients but were more common than in the controls. Mitoses were common in the intermediate tumour tissue in a few patients.

Basal cell carcinomas with areas of SCC had a greater prevalence of aggressive features (78\%) compared with the compact lobular, or keratotic tissue of BCCs (39\%). The difference was significant $(p<0.01)$. A similar difference in the prevalence of aggressive features was also seen between the con-

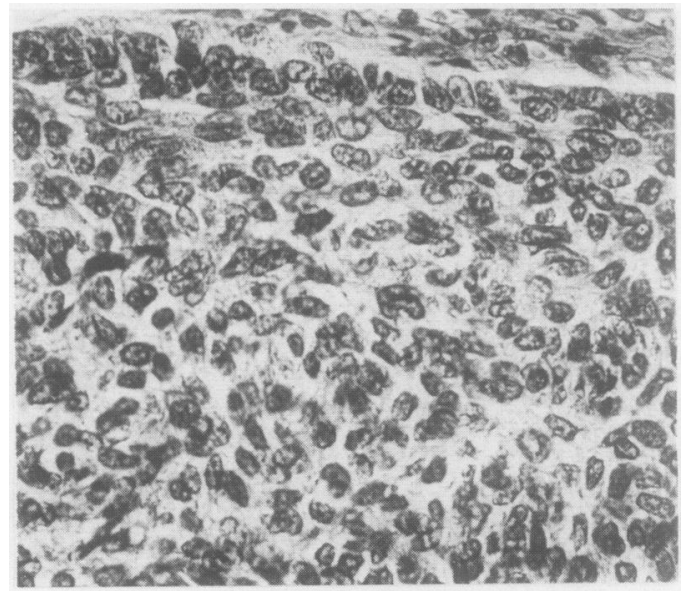

Fig. 10 Higher magnification of Fig. 6 of area (bottom right) showing typical picture of basal cell carcinoma (palisading at the top) $\times 320$.

trol BCCs with and without cell atypia (65\% v 40\%, $\mathrm{p}<0.05$ ). The control specimens were of both the compact lobular and keratotic types.

\section{Discussion}

In spite of the prevalent aggressive features and atypia of single cells in BCCs of compact lobular, or solid, and keratotic types, the change of these tumours into SCCs rarely occurred (3\%). In keratotic BCC the cell masses consisted of basal cells with squamous differentiation towards their centre; both basal and squamous cells were often uniform in appearance (Fig. 2). It must be said that the areas of SCC were not related to the epidermis or ulceration. They were deeply located, and exhibited the conspicuous pattern and cellular features of SCC (Figs. 7 and 8) rather than those of keratotic BCCs.

It is debatable whether a BCC with areas of SCC should be called basosquamous cell carcinoma. As previous studies have not provided an exact definition of a basosquamous carcinoma ${ }^{4}$ it is difficult to compare our findings with data from other authors. Exception is made for Burston and Clay, ${ }^{4}$ who defined the basosquamous carcinoma as a BCC differentiating into SCC. If their view is accepted the tumours reported here could also be called basosquamous carcinomas. Perhaps, for the time being, it would be better to use the descriptive term "basal cell carcinoma with areas of squamous cell carcinoma". The term "mixed carcinoma of the skin" is reserved for a tumour with two parts, one of BCC and the other of SCC, with both parts apparently independent in origin." In these tumours intermediate tumour is absent. 
The nature of this intermediate tissue is not fully understood. I considered it to be a transitional tissue and not an area of BCC with atypical cells. This theory is supported by the following features: differentiation of intermediate tumour into characteristic SCC; absence of peripheral palisading in most cell masses; more numerous atypical cells; and more infiltration borders. The local aggressiveness in the transitional carcinomatous areas was greater than that of typical BCCs $(p<0.02)$.

The finding in two patients of keratotic $B C C$ were similar to those of intermediate tissue. These cases may imply that BCCs with incomplete change into SCCs do exist.

If a BCC has small areas of SCCs these areas may go unnoticed in a routine biopsy. As the intermediate carcinomatous tissue is usually much more abundant the finding of this tissue should compel a search for areas of SCC.

The relation of BCC with areas of SCC to metastasising basal cell carcinomas requires further study. The metatypical pattern in metastasising $\mathrm{BCC}^{13}$ is similar to the transitional carcinomatous tissue outlined in this study.

\section{References}

' Okun MR, Blumental G. Basal cell epithelioma with giant cells and nuclear atypicality. Arch Dermatol 1969;89:588-600.
${ }^{2}$ Rupec M, Vallilzadh F, Korb G. Uber das Vorkommen von mehrkernigen Riesenzellen in Bäsaliomen. Arch Klin Exp Dermatol 1969;235: 198-202.

${ }^{3}$ Jacobs GH, Rippey JJ, Altini M. Prediction of aggressive behaviour in basal cell carcinoma. Cancer 1982;49:533-7.

4 Burston H, Clay RD. The problems of histological diagnosis in baso-squamous cell carcinoma of the skin. J Clin Pathol 1959;12:73-9.

s Montgomery H. Basal squamous cell epithelioma. Arch Dermatol 1928;18:50-73.

- Gans O, Steigleder G-K. Histologie der Hautkrankleiten. Vol II. Berlin: Springer Verlag, 1957:332.

' Borel DM. Cutaneous basosquamous carcinoma. Review of the literature and a report of 35 cases. Arch Pathol Lab Med 1973;95:293-7.

${ }^{8}$ Haber H, Symmers WStC. The skin. In: Symmers WStC, ed. Systemic pathology. Vol VI. 2nd ed. London: Churchill Livingstone, 1980:2596.

${ }^{y}$ Lever WF, Schaumburg-Lever G. Histopathology of the skin. 6th ed. Philadelphia: JB Lippincott, 1983.

${ }^{10}$ Pinkus H, Mehregan AH. Tumoren der Haut. In: Doerr W, Seifert G, Uehlinger E, eds. Spezielle pathologische Anatomie. Vol VII. Berlin: Springer Verlag, 1973:559-65.

"Allen AC. Skin. In: Anderson WAD, Kissane JM, eds. Pathology. Vol II. 7th ed. St Louis: CVB Mosby, 1977:1802-73.

${ }_{12}$ Ashley DJB. Tumors of the Integument. In: Ashley DJB, ed. Evan's histological appearances of tumours. 3rd ed. Edinburgh: Churchill Livingstone, 1978:342-436.

${ }^{13}$ Farmer ER, Helwig EB. Metastatic basal cell carcinoma: clinicopathologic study of 17 cases. Cancer 1980;46:748-57.

Requests for reprints to: Dr J Lopes de Faria, Department of Anatomical Pathology, Faculdade de Ciências Medicas, UNICAMP, Campinas, SP, Brazil. 